\title{
MECHANISMS FOR THE INTEGRATION OF TOURISM SYSTEMS: TYPES, PROBLEMS, PROSPECTS
}

\author{
Volodymyr K. FEDORCHENKO* \\ Kyiv University of Tourism, Economics and Law, Department of Theory and Practice of Tourism and Hospitality, Kyiv, Ukraine, e-mail: v.fedorchenko@uohk.com.cn \\ Oleg V. PARUBETS \\ Kyiv University of Tourism, Economics and Law, Department of Theory and Practice of Tourism and Hospitality, Kyiv, Ukraine, e-mail: ovparubets@nuos.pro \\ Ludmyla Yu. KRASAVTCEVA \\ Kyiv State College of Tourism and Hospitality, Department of General Theoretical and Applied Preparation, Kyiv, Ukraine, e-mail: prof.krasavtceva07@tanu.pro
}

\section{Ludmyla V. HRYBOVA}

Kyiv State College of Tourism and Hospitality, Department of Tourism and Hotel and Restaurant Business, Kyiv, Ukraine, e-mail: hrybova89@uohk.com.cn

\section{Oleksandr A. KRUCHEK}

National University “Odessa Law Academy”, Kyiv Institute of Intellectual Property and Law, Department of Constitutional, Administrative and International Law, Kyiv, Ukraine, e-mail: o-kruchek@nuos.pro

\begin{abstract}
Citation: Fedorchenko, V.K., Parubets, O.V., Krasavtceva, L.Yu., Hrybova, L.V., \& Kruchek, O.A. (2020). MECHANISMS FOR THE INTEGRATION OF TOURISM SYSTEMS: TYPES, PROBLEMS, PROSPECTS. GeoJournal of Tourism and Geosites, $32(4)$, $1229-1237$. https://doi.org/10.30892/gtg.32406-562
\end{abstract}

\begin{abstract}
Tourism systems can be defined as a component of a geographic information system or a regional economic development system. The article aims to study the tourist system as an element of the integration mechanism between states. To solve a wide range of optimisation problems in logistics, the methods of linear programming and integer programming were used. The authors propose a model that allows to integrate tourist routes into the structure of tourist flows both within the country and internationally. The economic consequences of the use of information systems in tourism will create additional value and ensure regional development.
\end{abstract}

Key words: tourism, globalisation, information, development, formation

\section{INTRODUCTION}

In the context of globalisation, the countries of the world are undergoing processes of transformation and reorganisation of all areas of managerial activity, and the role of tourism enterprises in these modern conditions is determined by special relevance due to a number of technological, economic, political, social, cultural problems from the integration and information and communication progress that creates objective conditions for both the unification of society and its separation (Liying, 2018; Sakulyeva, 2020). At the same time, globalisation acts as a transition to the politics of supranational organisations (UN, NATO, G8), in the economy - transnational corporations and supranational bodies (World Bank, UNWTO - United Nations World Tourism Organisation), the formation of global international economic and political structures, which opens up significant prospects for the study of these processes (Song, 2017).

A volatile globalisation space requires tourism enterprises to adapt to rapid economic, political, and social changes through the use of new principles and modern methods for effective governance (Damian \& Suárez-Barraza, 2015). This is manifested in the reorganisation of the management of tourism enterprises, the expansion of financial, cultural, social, sales, resource and labour markets, the increase in the share of foreign direct investment in developing economies, the expansion of the labour market, the diffusion of technology, communications, and global cultural integration (Yuexi \& Feng, 2018; Rudenko, 2018).

The globalisation problems of the 21 st century are still little explored and need analysis, and many countries are not ready to adapt to the rapid changes in modern scientific and technological progress, structural changes in the world market and sociocultural transformations of society that form the geopolitical, geo-economic, geo-cultural space for the development of states (Błażejowski et al., 2019). The symptomatology of these processes must be studied at the level of world prerequisites, state transformations and the reorganisation of managerial processes of enterprises in various areas of production activity (Song, 2016; Fedotov et al., 2018). A fundamental study of the theoretical and methodological approaches of globalisation phenomena or social processes should be started with the disclosure of the categorical-conceptual apparatus, methodological understanding of the individual components of the problem to determine the basic laws and concepts with the help of which it is possible to analyse certain influential problems in society (Sharifzadeh et al., 2020). The content of the concept of "globalisation" remains the subject of heated debate, causing a clash of different, sometimes even diametrically opposing points of view, and is explained by two reasons (Smoliy et al., 2006; Towner, 2016). First, the process of globalisation has begun relatively recently and it is not possible to fully assess its consequences (Carmignani \& Moyle, 2019). Secondly, the deployment of this process leads to exacerbation of contradictions in the global economy, affects the interests of its various actors (Wondirad et al., 2020; Sayabaev et al., 2016). It is not surprising that sometimes social forces in every way welcome and promote economic globalisation, while others criticise it sharply.

In the economic sense, the development of enterprises in the modern geo-economic space is impossible without considering the internal and external management process (Coca-Stefaniak, 2019; Basiurkina et al., 2020). The modern economic space, the parameters of which must be determined, combines not only real business processes but also transcendental elements of their activity, which are still in their infancy, and therefore remain theoretically unreasonable, outside the boundaries of the visible process and institutional definitions. Each complex process that takes place in society requires its decomposition into simpler ones in order to fully comprehend them (Li, 2017, Shtal et al., 2019).

\footnotetext{
* Corresponding author
} 
That is, a constant analysis of changes in globalisation phenomena is necessary that directly affect the activities of a tourism enterprise and lead to reorganisation changes in their management and understanding of the essence of globalisation paradigms for applying universal methods and principles for making evolutionary decisions in modern management of tourism enterprises, provide grounds for determining evolutionary the origin of managerial thought (Prabpriree et al., 2016; Diekmann \& McCabe, 2016).

From the beginning of the last century (i.e., the moment the theory of control was born) and until the 1960s, management prin ciples were constructed in a closed manner (Todd et al., 2017; Shtal et al., 2018). Only with the development of society, the complexity of products, the growth of high-tech industries, management science began to approach the problems arising from the fact that the work of tourism enterprises is largely determined by the external environment (Akay, 2020). Management science developed by analysing the experience of American schools, and the practical application of developments was constrained by the lack of needs of manufacturers and the underdeveloped market environment (Qian et al., 2019; Rudenko et al., 2016).

Studying the realities and tracing the patterns of the globalisation phenomena influence on the development of enterprises provides ground for considering the theoretical and methodological foundations and fundamental analysis of the management paradigm (Hair et al., 2019; Khytrova et al., 2020). Successful solution of these problems will allow to determine competitive advantages and directions for the effective use of the internal resource potential of enterprises. So, the relevance of this study makes it possible to speak about the tourism system as a component of sustainable development in the socio-economic environment.

\section{METHODOLOGY}

The tasks associated with routing are carried out by simple and effective heuristic methods that allow to quickly find the needed solution, but it does not guarantee to find the optimal solution (Kavun et al., 2015). As a rule, to solve a wide range of optimisation problems in logistics, the methods of linear programming (LP) and integer programming (IP) are used. The work focuses on the economy of the tourist route and combination of the heuristics flexibility and mathematical modelling using cyclic programming, which allows to get the best or at least probably the best solution. This combination is called the unified optimisation methodology (Sherali \& Driscoll, 2019). The combination of these two methods will help to solve and ease many issues when creating a formalised model. Firstly, to describe the sequence and priority of excursion objects, that is, to determine the priority of one of them. Secondly, cyclic programming and integer programming will help to develop a selection of several optimal route options for a series of variable indicators.

The paradigms of the modern development of enterprise management are not possible in the current interpretation, but require radical changes in their application (Lin, 2018). Evolutionary methods that fundamentally direct the effective management of tourism enterprises in the globalisation space are reflected in a combination of the methodological achievements of several paradigms (Backer \& Ritchie, 2017). That is, the following modern methods can be distinguished (Raj Sharma \& Bisht, 2018):

- A systematic method that allows to consider the management of a tourism enterprise as a set of laws, principles that constantly interact with the environment.

- Synergetic method - it shows that in the globalisation space it is impossible to use linear control of systems (state, tourism enterprises) since economic, political, sociocultural phenomena are chaotic. Therefore, it is necessary in modern conditions in the management of tourism enterprises to apply a combination of synergetic and systemic methods, which allows to explain the features of the development of the management system in the usual and catastrophic modes of exposure to the globalisation environment.

- Structural, functional and institutional methods allow to reveal the content of exogenous and endogenous shifts in society.

\section{RESULTS AND DISCUSSION}

The developed algorithm for designing and organising a tourist route represents an enlarged model (Figure 1), on the basis of which an effective tourist route is formed, unlike existing ones, it makes it possible to define excursion objects and describe their sequence of visits by priority, cost, time, length of the route thread and make a selection of route options for a number of variable indicators and determine the optimal priority tourist route.

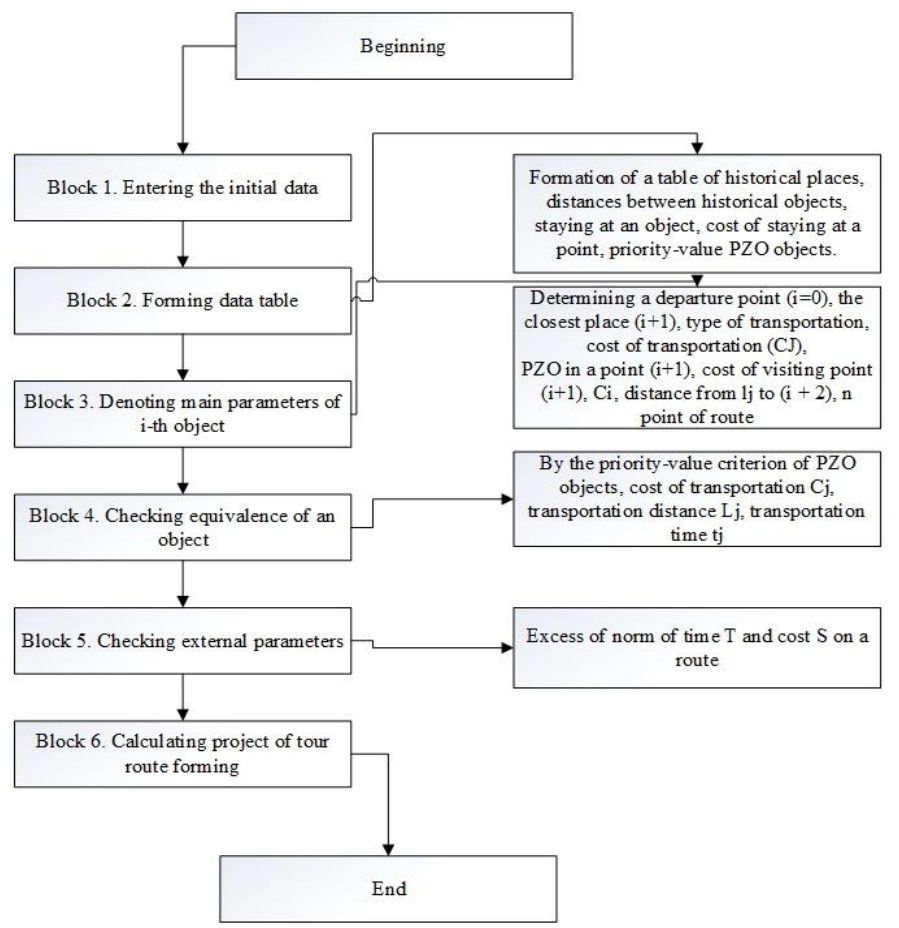

Figure 1. The enlarged block - a diagram of the algorithm for the formation of a tourist route (Source: authors' own research based on Rudenko et al., 2019) 
The developed algorithm allows to solve complex marketing, organisational and design tasks that are posed during the formation of a tourist route. The model for the formation of a tourist route involves the use of algorithm modules, with set theory, namely, using mathematical and cyclic programming, they helped to determine the priority areas of the route and apply the sequence of selected objects on a priority scale. This made it possible to develop a selection of several optimal route options for a number of variable indicators, which form their own factor group on the basis of the software that allows to take into account all the criteria for choosing an effective route, while using all incoming tabular data. Therefore, for a more detailed presentation of the stages of each block on a formalised model, a block diagram of a formalised model for the formation of a tourist route was used. In this case, such variables are: the number of objects $u=0+n$; time spent in each one $-t$; price $C i$ - visiting the i-th object; the cost $C j$ of transporting tourists by $j$-ous means of transport.

The tourist route formation algorithm is formed from blocks. Block 1 generates the source information. It uses tables of such source data:

- formation of a table of possible historical places (Block 2);

- formation of a table of distances between points (Block 3);

- formation of a table of possible time spent at a point (Block 4);

- formation of a table of historical value at a point (Block 5);

Block 6 provides for the formation of a table of the cost of staying at a point.

Block 2 means the formation of a database of all historical sites and recreational potential in each of the places. The design of a tourist route involves the implementation of a set of actions, which are described in Block 1, which allows using the formalised model to simplify the complexity of actions when they are performed. Block 3 means that on the basis of the selected objects from a certain territorial zone using the Business Map program, a sample of the allowable minimum distances between the selected objects is calculated. Block 4 means using the approximate time spent by a tourist at a historical point. This table is based on research data on the provision of excursion services and is formed as the average time spent at this point. Block 5 means an assessment of the historical value of the selected objects according to the criteria of the largest visits in a ballistic sense. Block 6 means the formation of a database of the average price of the service (excursions in a particular object). Based on the previous blocks (source data), we proceed to Block 7, which means choosing a different optimal departure point for the tourist group from which the beginning of the model and route will be formed. Block $8-$ selection of the nearest point (historical object) to the point of departure. The whole stage of the route economy and the choice of transport or method of transportation to the selected objects depend on Block 9. Depending on the object, city or region, different types of transport can be used, the tariffs for transportation of which depends on the following variables: the number of persons transported (N); distance between objects (l), which forms the total distance along the route, $\mathrm{L}$; total time spent on the route $(\mathrm{T})$.

Based on this, the initial table of the database with the tariffs of Block 10 for passenger transportation by various modes of trans port according to variable criteria was established (Table 1).

Table 1. Tariffs for the carriage of passengers by road (Data source: authors' own calculations based on Mazur, 2019)

\begin{tabular}{|c|c|c|c|c|c|c|c|}
\hline \multicolumn{2}{|c|}{ Transport passenger's capacity } & $\mathbf{5 - 9}$ persons & 19 persons & 22-43 persons & 30-36 persons & $\mathbf{4 7 - 8 2}$ persons \\
\hline \multirow{3}{*}{ Passenger transportation } & Price per hour, USD & 80 & 90 & 150 & 170 \\
\cline { 2 - 6 } & \multicolumn{3}{|c|}{ Minimum rental time 3 hours } \\
\cline { 2 - 6 } & Minimum price per hour, USD & 200 & 250 & 400 & 500 & 600 \\
\hline
\end{tabular}

Distances between cities are calculated using a computer program that is based on satellite communications, where all maps and programs are shown, with which the distance between cities is calculated. With the help of expert research, block 11 is formed. When the first object on the route is fully explored, the authors gradually proceed to the excursion object $i+1$ by adding the numbers to $i(0,1,2,3 \ldots$. 4). That is, the first object has a serial number $0+1=1$; the second $1+1=2$; the third $2+1=3$, and so on. If the historical value of the first object is higher than the others, then it is necessary that its serial number be greater than the serial numbers of another object.

Turn to Block 12, where the next distance to the nearest historical object on the route is investigated. Again, Block 13 investigates the type of movement and proceeds to determine the historical value of the object. Block 15. If at this stage among the previously selected points there are points (objects) of equal priority, we return again to Block 15 and we find the following historical value of the route point. At the same time, the following selection criterion, of two equally historically valuable objects, is the minimum cost of staying in it (Rogerson \& Rogerson, 2019). The authors proceed to identify the next minimum distance to the nearest historical object on the route. The authors again examine the type of movement and proceed to determine the historical value of the object. If at this stage among the previously selected points there are points of equal priority, then it is worth to return again to Block 2 of module 1 and find the following historical value of the route point. Moreover, the next selection criterion, from two equally historically valuable objects, is the minimum cost of staying in it.

If $i+2 \rightarrow \max C i$ of $\mathrm{i}$-th object goes to block 2 , module 1 , and exclude this point. If the $i+2 \rightarrow \operatorname{minC} i$-th object, the authors proceed to the next test and calculate its historical value and proceed to the choice of the next object. Block 3 provides for the verification of the following selected points. They are examined by: historical value and determine the most valuable points; by the criterion of the time spent at the point. If there are no points of equal historical value, then the authors proceed to determine the cost of moving. If the time spent at the point exceeds the time limit, then this point is excluded from the route and proceed to determine the total cost of the route. If the time does not exceed the limit, then the total time on the route is calculated.

Block 21 provides for checking the identity of objects by distance, if such a point is found, then go to Block 22 and return to the previous point. If this object is not found, then go to Block 23 and again select the type of movement. Researching the next point of Block 24 determines the historical value of objects and if similar objects are found, then the authors go to Blocks 25,26 and 27 , where the most valuable point is determined. At this stage of selecting an object, a new criterion appears: the choice of time to stay at a point is Block 29. The time to visit each historical object is different, therefore, depending on the recreational object, the tourist spends a different time period. A table for visiting historical places (objects) is designed as a time card. If in Block 25 there are no points of equal historical value, then go to block 28 and determine the cost of moving. If the time spent at the point exceeds the specified parameters, then the authors from Block 30 go to 31 and exclude this point from the route and go to Block 34 to determine the total cost of the route. If the time does not exceed the specified parameters, then in Block 32 the total time on the route is calculated according to the formula (Damian \& Suárez-Barraza, 2015):

$$
T_{H}=\sum_{i=1}^{n} t_{i}+\left(t_{1}+\frac{L_{z a g}}{V_{m}}\right),
$$


where: $t_{i}$ - average time of stay of a tourist in a historical object, min.; $t_{l}$ - average travel time, min .; $L_{z a g}$ - distance of movement of passengers, $\mathrm{km} ; V_{m}$ - the average speed of transport around the city, $\mathrm{km} / \mathrm{h}$. This formula is used if tourists are transported by road (bus). The total cost of the route is determined according to the formula (Damian \& Suárez-Barraza, 2015):

$$
C=\sum_{i=1}^{n} Z_{i}+B, \quad \text { Equation 2 }
$$

where: $Z_{i}$ - the average price of visiting a historical site, dollars; $B$ - total cost of transportation of tourists, dollars.

Figure 2 presents a working block diagram of an algorithm for the formation of an effective tourist route. The algorithm is based on additional software modules, each of which forms its own separate factor group that allows to take into account all the criteria for choosing the thread of an effective route and at the same time use all incoming tabular data. Modular blocks make up such a basic sequence: determining the total priority of the object of visit; cost formation between objects of visit; formation of total costs between objects of visit; ordering objects by priority; the probability of the formation of all routes on the priority territory of a trip; route selection with a limited total travel time; determination of the total cost of the selected route. Analysis of the project is the final stage of its design. It is carried out by representatives of corresponding functional units of a tourism enterprise. It aims to identify and timely eliminate inconsistencies in a project. The result of the analysis is the updated content of the technological documentation of the tourism company.

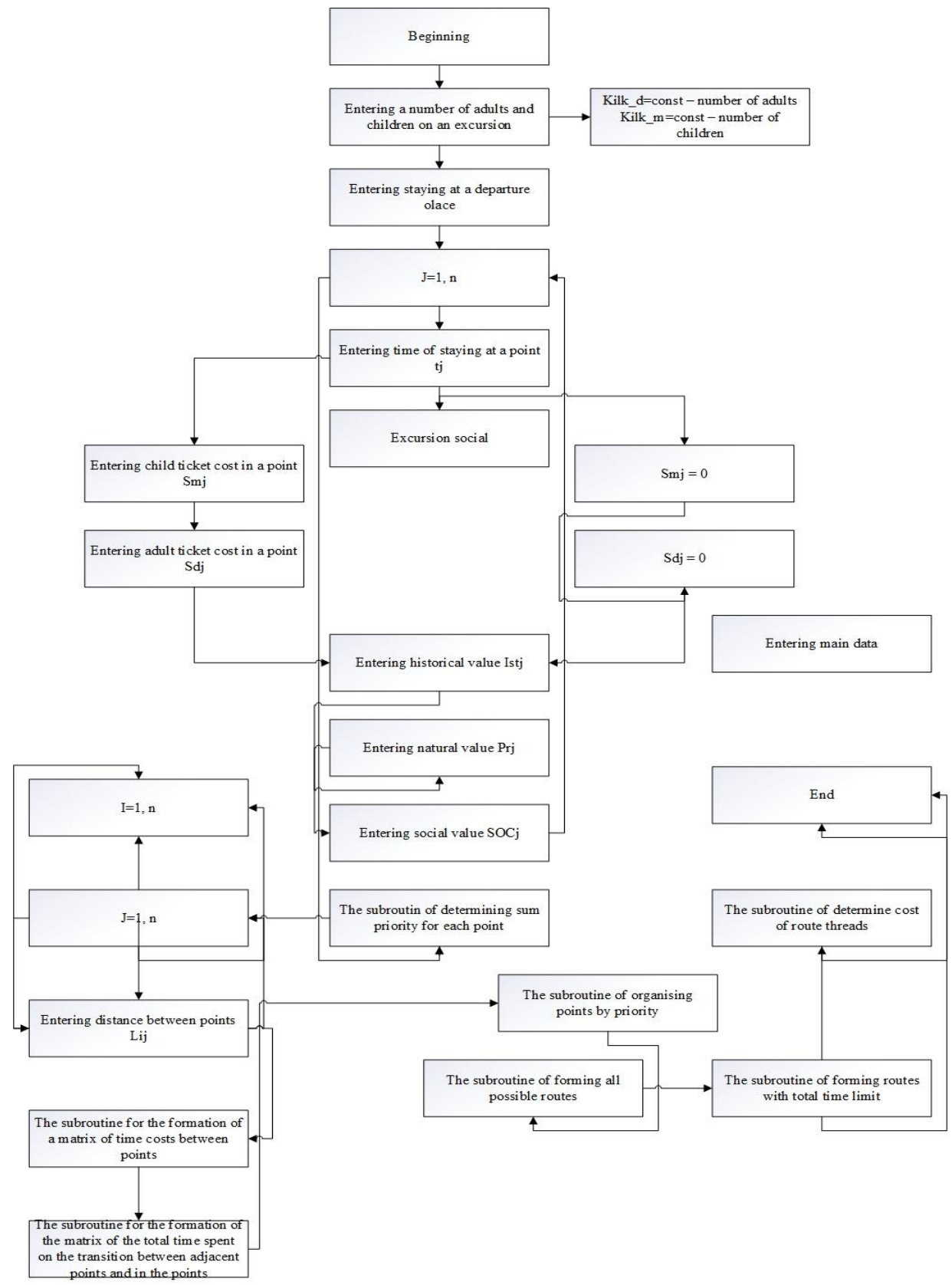

Figure 2. The working block diagram of the formation of the tourist route (Source: authors' own research based on Lin, 2018)

After passing through all the stages of creating routes, the authors proceed to block 35, which contains the design of the route, that is, the execution of all documents: 
1. Drawing up a contract for the provision of excursion services. This is an organisational issue for the provision of qualified excursion services to a group of tourists. Tourism organisers are obliged to use the services of qualified tour guides (guides, guide-interpreters) who have the proper license or accreditation of an object (museum, temple, monastery, another object of the tourist display of the national park).

2. Registration of a contract of tourism organisers or individual tourists (excursionists) with persons providing services of a guide (guide, guide-translator).

3. The conclusion of a contract (accession to a contract) for the provision of excursion services is certified by an excursion ticket. The form of the tour voucher is determined in the manner prescribed by the authorised state tourism authority. A person who provides excursion services must, before concluding an agreement, provide the tourism organiser with the necessary and reliable information about the touristexcursion company, the excursion bureau, about the services, their types and features, the qualification of the guide, about the procedure and terms for paying for the services (Kifyak, 2019).

The stage of designing a tourist route is completed, which is provided for by Block 2, where the following successive stages are provided for in the algorithm for designing and organising a tourist route: establishing standardised characteristics of the service; the establishment of technology for the process of serving tourists; development of technological documentation; definition of quality control methods; project analysis; submission of the project for approval.

The result of the design of tourism services are technological documents (routings, rules, instructions). The documentation on quality control should establish the forms, methods and organisation of control over the implementation of the process of servicing tourists in order to ensure its compliance with the planned characteristics. In order for the model of the formation of an optimal tourist route (FOTM) to work efficiently, its qualitative implementation is necessary, which is able to ensure the effective functioning of all enterprises in the tourism industry. This will help to reduce the cost of tourism enterprises (tour operators, tourist excursion bureaus) to obtain a tourism product from tour operators. A comprehensive assessment of tourist routes led to the creation of two models: the first - an assessment of the priority area of tourist travel; the second - the phased formation of a rational thread of the route. The use of a model for the phased formation of a rational route thread involves the creation of software that is based on computer technology (Figure 3).

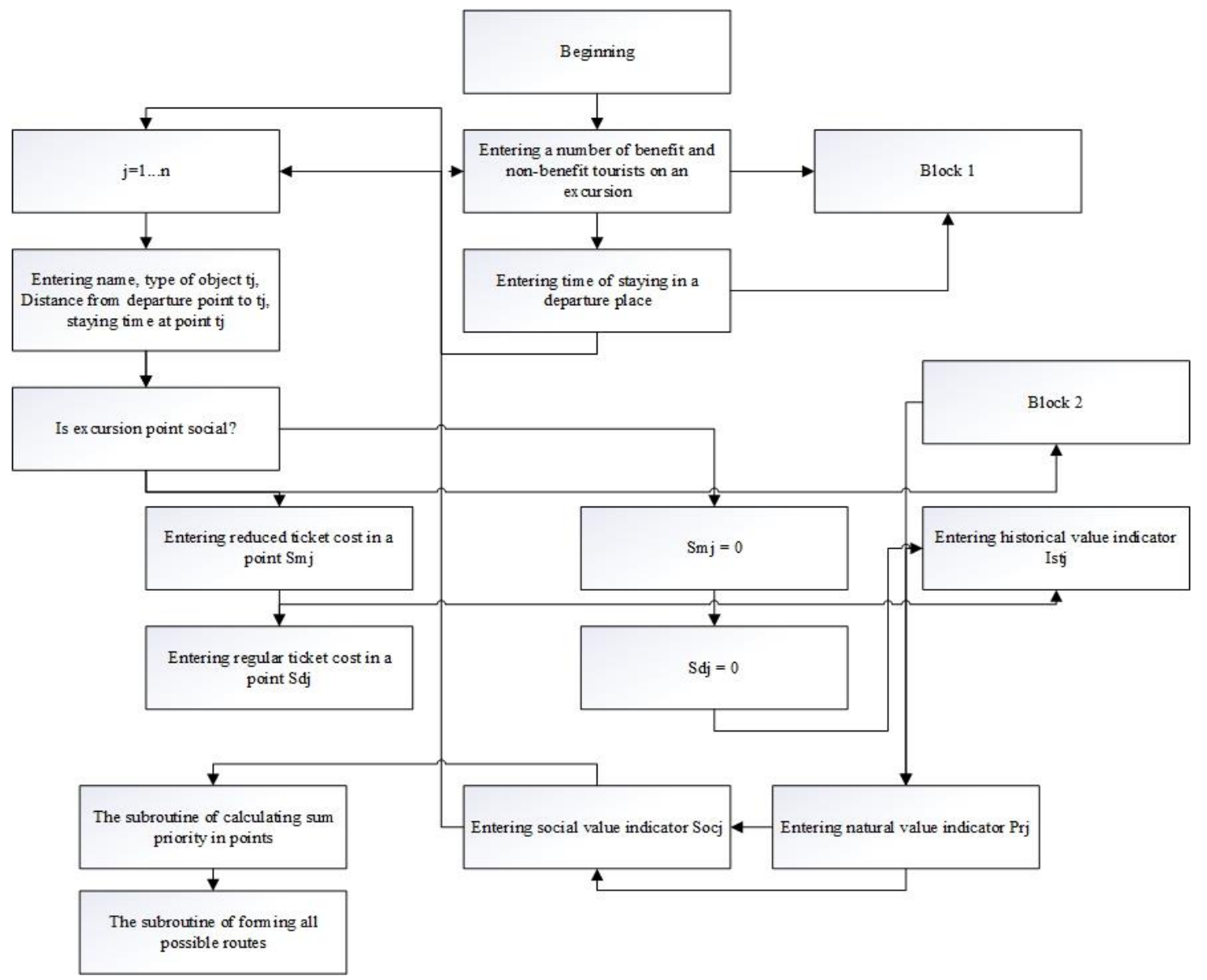

Figure 3. The block diagram of the program for the implementation of the task of finding a rational tourist route (Source: authors' own research based on Rudenko et al., 2019)

Block 1. Data on the number of adults and children on the tour are entered. The cost of the excursion depends on these data, because if the ticket price at the excursion point is preferential for children, this affects the cost of a tour. At the same time, an assessment of the priority area of a tourist trip allows, based on an analysis of the identified tourism potential, to develop recommendations on promising areas of tourism development in the regions to identify reserves for their further growth. As a result of the study of the assessment of the priority travel area, it was found that the most actively used objects were of cultural heritage, rivers and lakes for summer educational and sports tours. The number of tourists without benefits is determined by the formula (Song, 2017):

$$
\text { Kilk } d=\text { const, }
$$

where: Kilk_d - the tourists without benefits; const-permanent value. The number of tourists with benefits is determined by the formula (Song, 2017): 


$$
\text { Kilk_m }=\text { const } \quad \text { Equation } 4
$$

where: Kilk_m - the tourists with benefits.

According to the conditions of the task, this amount is unchanged throughout the thread of the route, at each point. Only two types of excursionists are considered - beneficiaries (children, students, pensioners and other categories considered by law) and not beneficiaries. Next, in Block 1, the value of the time spent at the point of departure is entered. It is taken equal to 20 minutes. This value affects the total time of the route, therefore it must be fixed and defined. Block 2. The values of the time spent at each point are entered, and it is also checked whether the excursion point is social. For this: a cycle is started according to the number of probable route points; input vector - a column of names of probable objects; a vector is introduced - a column of distances from the departure point to each probable route point; the input vector is the column of the time spent at each point, determined by the formula (Song, 2017):

$$
t=t_{1}, \ldots t_{n}, \quad \text { Equation } 5
$$

where: $t_{1}$ - time spent at the first point of the route, $\min ; t_{n}$ - time spent at the next point of the route, min. $t$ - the condition is checked whether the excursion point is social. To do this, a priority rank of 1 and 0 is entered. If the point is social, the indicator is 0 , if commercial 1. Entering the cost of a reduced ticket (Sm) (Song, 2016):

$$
S m_{j}=\left\{\begin{array}{cc}
S m_{j}, S_{j}=1 \\
0, S_{j}=0
\end{array} \quad \text { Equation } 6\right.
$$

The cost of a non-preferential ticket is entered in the following order (Song, 2016):

$$
S d_{j}=\left\{\begin{array}{c}
S d_{j}, S_{j}=1 \\
0, S_{j}=0
\end{array}\right.
$$

- introduction of an indicator of historical value, $I s t_{j}$;

- introduction of natural value $\operatorname{Pr}_{j}$;

- introduction of an indicator of social value, $\operatorname{Soc}_{j}$;

- completion of the cycle after the transition to all numbers of probable points on the route.

The subroutine for calculating the total priority in points provides the following actions:

1. A matrix of dimension $m \times n$, is created, where $m$ - the number of rows, $n$ - the number of columns in those rows (point numbers), values are set for each column. The column number carries information about the type of value: $1-$ historical; 2 - natural; 3 - social. Quantitative indicators of value vary from 1 to 3 for each type of value.

2. The cycle on $i$ runs on. The line number is fixed.

3. The initial value of the sum for each point is taken equal to $\operatorname{Sum}=0$.

4. The cycle on $j$ begins.

5. For each point, the sum of the historical, environmental and social values of the point is calculated according to the formula (Liying, 2018; Lin, 2018):

$$
\operatorname{PrSum}_{j}=\sum_{j=1}^{n}\left(\operatorname{Ist}_{j}, \operatorname{Pr}_{j}, \text { Soc }_{j}\right), \quad \text { Equation } 8
$$

where: Ist - historical value of the excursion object; $P r$ - the natural value of the excursion object; Soc - social tourist sites.

6. After adding all the values in the row by columns, the cycle on $j$ closes, the value of the sum fills a new place in the column vector created from the values of the sums of the current row.

7. Proceeding to the next line.

8. After enumerating all the point numbers, the cycle closes.

The routine for the formation of all probable routes a matrix of possible routes between points is created. By $i$ and by $j$, values of probable transitions between points are introduced. Where: $i$ - the number of the previous point; $j$ - number of the next point. Thus, there are many possible options for transitions between points. This is preliminary data, because no restrictions are taken into account. Probably the matrix is shown in the form of equation (Liying, 2018; Lin, 2018):

$$
C_{i, j}=\begin{array}{cccccc} 
& t_{1} & t_{2} & \ldots & t_{n-1} & t_{n} \\
t_{1} & 0 & c_{1,2} & \ldots & c_{1, n-1} & c_{1, n} \\
t_{2} & c_{2,1} & 0 & \ldots & c_{2, n-1} & c_{2, n-1} \\
\ldots & \ldots & \ldots & 0 & \ldots & \ldots \\
t_{n-1} & c_{n-1,1} & c_{n-1,2} & \ldots & 0 & c_{n-1, n} \\
t_{n} & c_{n, 1} & c_{n, 2} & \ldots & c_{n, n-1} & 0
\end{array}
$$

Equation 9

By $i$ and by $j$, values of probable transitions between points are entered: where: $i$ - number of the previous point; $j-$ number of the next point. Thus, there are many possible options for transitions between points that are shown in the matrix (Liying, 2018; Lin, 2018):

$$
L_{i, j}=\begin{array}{cccccc} 
& t_{1} & t_{2} & \ldots & t_{n-1} & t_{n} \\
t_{1} & 0 & l_{1,2} & \ldots & l_{1, n-1} & l_{1, n} \\
t_{2} & l_{2,1} & 0 & \ldots & l_{2, n-1} & l_{2, n-1} \\
\ldots & \ldots & \ldots & 0 & \ldots & \ldots \\
t_{n-1} & l_{n-1,1} & l_{n-1,2} & \ldots & 0 & l_{n-1, n} \\
t_{n} & l_{n, 1} & l_{n, 2} & \ldots & l_{n, n-1} & 0
\end{array}
$$


For this, two cycles by $i$ and $j$ are launched. Block 3. Entering distances between points. A matrix of probable distances between points is created. The subroutine for the formation of a matrix of time costs for moving between points:

1. The cycle starts by $i$ and by $j-$ the previous and next point.

2. The condition is checked whether the distance between the points is greater than $0.7 \mathrm{~km}$. If more, then the movement between the points occurs in transport, the speed of which is $40 \mathrm{~km} / \mathrm{h}$. If less, then the excursionists move from one point of the route to another on foot. In this case, the speed $\left(V_{i j}\right)$ is $4 \mathrm{~km} / \mathrm{h}$ (Damian \& Suárez-Barraza, 2015):

$$
V_{i, j}=\left\{\begin{array}{c}
40, l_{i, j} \geq 0.7 \\
4, l_{i, j} \leq 0.7
\end{array},\right.
$$

Equation 11

3. The value of the time spent moving between the points $t($ per $)$ is calculated, which is determined by the formula (Damian \& SuárezBarraza, 2015):

$$
\text { tper }_{i, j}=\frac{l_{i, j}}{v_{i, j}},
$$

where: $l i, j$-distance between objects, $\mathrm{km} ; \boldsymbol{V} \boldsymbol{i}, \boldsymbol{j}$ - average speed of transport, $\mathrm{km} / \mathrm{h}$.

4. An explanation matrix is formed - on foot or by transport, excursionists move between points (Damian \& Suárez-Barraza, 2015):

$$
\operatorname{Rem}_{i, j}=\left\{\begin{array}{l}
j_{i, j}<0.7 \\
l_{i, j} \geq 0.7
\end{array},\right.
$$

After recalculations, a time-expenditure matrix is formed at all points, after which the cycles are closed. The subroutine for the formation of the matrix of the total time spent on the transition between adjacent points and in the points themselves:

1 . The cycles by points $i$ and $j$ are opened.

2. The sum of the time spent at each point and the transition between points is found. It should be noted that the stay at each point is described by a vector, and the transitions between adjacent points by a matrix. Therefore, the total time spent on the route is formed by the formula (Damian \& Suárez-Barraza, 2015; Lin, 2018):

$$
t_{z a g_{i, j}}=t_{p e r_{i, j}}+t_{i}
$$

where: tperi, $j$ - time to move between given points, hours., (min.); $t i$ - time to visit the $i$-th point, hour., (min).

3. After using all the actions, a matrix $t_{z a g}$ is formed.

4. The cycles are closed.

The subroutine for forming an array of numbers of points minimum in distance from zero:

1. A value is set that in advance is less than the probable value in the array.

2. The initial value for the accountant of the number of points with the smallest distance from the initial is set equal $0, k=0$.

3. A cycle is set by $j$ for sorting through all elements of the array from 1 to $n$.

4. A condition is set for checking whether the element of the array $r$ is less than the minimum and, if the condition is satis fied, the minimum value takes the current value.

5. If the condition is satisfied, the counter is turned on to determine the number of the minimum element of the array $\mathrm{kl}$, the minimum value is assigned - the value of the distance to the current point and the array dovg_min is formed of the numbers of minimum values.

6 . There can be several such values, therefore the number of such values is deduced.

The subroutine for forming an array of numbers of highest priority points.

1. A value is set that in advance is less than a probable value in the array $\min =l E-5$.

2. The initial value of the number of maximum points equal to 0 is set.

3. The cycle is launched to iterate over all elements of the array prsum - total priorities.

4. The condition for checking: is there the array element prsum and is greater than the maximum.

5 . The cycle closes, a new one opens for the same number of elements $(j=1 \ldots \mathrm{m})$.

6. All elements of the array are checked for their equality with the maximum. If the condition is satisfied, the counter is turned on to determine the number of the maximum element of the array $k 2$, the maximum value and the distance value to the current point are assigned, and an array prior_max is formed of the numbers of maximum values.

7. The cycle closes.

The subroutine of finding matching points in terms of priority and minimum distance. Two arrays are checked from the selected point numbers by priority and distance, or they are the same. After the first match, the point number is fixed; sampling is stopped. If there is no match and the first point is taken, the first one closest to zero:

1. The cycle by i opens.

2. The cycle by j opens.

3. The condition is checked (Liying, 2018; Lin, 2018):

$$
\text { First_point }=\left\{\begin{array}{l}
\text { prior_max }, \text { dovg_min }_{-} \text {prior_max }_{-}, \\
\text {dovg_min, dovg_min } \neq \text { prior_max }
\end{array}\right.
$$

Equation 15

4. The cycles close.

5. The values of the first point after the zero and its name are displayed.

After the first point of the route was found, it is necessary to find the entire thread of the route. This will happen by enu merating all the distances between the points. In each column there is a minimum value and in the next columns the elements of the rows in which these values are located are replaced by a number, that is, such that in any case there will be more array element. The subroutine of finding the first point and excluding it from the selection of the future route. The value of the column number is set to 1 , that is $j=1$ :

1. The cycle is opened by $i$, that is, all elements of the column are sorted by rows. 
2. The condition is checked whether the line number coincides with the number of the first point after zero, or not. If it matches, the element of the first column is assigned equal to tm, if it does not match - equal to the output value (Liying, 2018; Lin, 2018):

$$
\text { First_point_Intro }{ }_{i, 1}= \begin{cases} & t m " i=\text { First_point }, \\ L_{i, 1, i} \neq \text { First_point } & \text { Equation } 16\end{cases}
$$

3. The cycle repeats until all the lines have been sorted. Then the cycle closes.

A subroutine for forming a matrix in which all values that belong to the location line of the first point are indicated $1 * E^{5}$ :

1. The cycles are started first in rows $(i)$, then in columns $(j)$.

2. The condition is checked, either it is equal to the row number First_point or the value is 0 . If the condition is satisfied, the element is given a value $1 * E^{5}$, if not - the value of the element of the distance array.

3. All the elements of the matrix are iterated in cycles. The cycles close.

The subroutine for generating a vector from minimum column values. One of the tasks of this subroutine is that in each subsequent column those lines in which values were found are not used. This is due to the fact that excursion points cannot be repeated on the route thread (Mazur, 2019; Denissova et al., 2018). In this subroutine, two vectors are formed - one of the numbers of the minimum elements, and the second directly from these elements. The order of numbers is the very thread of the route, because it determines the previous and next point:

1. The cycle by columns $(j)$ opens.

2. The previous value of the minimum element is affected such that it is in advance larger than any value in the matrix, $\min =1000$.

3. The cycle by rows $(i)$ starts.

4. Whether the column is the first is checked. Indeed, if the condition is confirmed, in this column the value of the line number in which the point is located is known and equal First_point.

5. The row number is entered in the vector Nom_min_stov $p$, which is formed from the numbers of elements.

6. In the event that the column number is different from 1, the following conditions are checked: whether the element is less than the minimum row, and (or); or there was a minimal element in this row in the previous columns.

7. If the condition is true, min is provided to the value of this element.

8. The value of the element that satisfies the condition is assigned equal $1 * E^{5}$.

9. If any of the conditions is false, the next element is taken.

10. All the values are iterated and the cycle by i closes.

11. The minimum value is assigned to the element of vector; its number is entered in the vector Nom_min_stov $p$ and values in the vector Znach_min_stov $p$.

12. The cycle by $\mathrm{j}$ closes.

The subroutine for calculating the time spent on the route. To calculate the time spent on excursions, first it is necessary to select from the matrix $t_{z a g}$ those values that belong to the rows of the column numbers of the minimum elements Nom_min_stov $p$, creating a new vector from them $t_{\text {pereb }}$, and then find their sum:

1 . The cycle starts in columns.

2. The initial value of the number of elements is 0 .

3. The cycle starts by row.

4. The condition is checked whether the element number of the total time row $t_{z a g}$ matches the number of the minimum element in distance Nom_min_stov $p$.

5. If it matches, then the counter $k=k+1$ is turned on and a new array is formed $t_{\text {pereb }}$. Exiting the cycle $i$.

6. If it does not match, the next item is taken.

7. After iterating over all the rows, go to the next column.

8. Exiting the cycle.

9. The sum of the elements of the array $t_{\text {pereb }}$ is found.

The total time $T_{\text {sum }}$ spent on the tour is determined by the formula (Damian \& Suárez-Barraza, 2015):

$$
T_{\text {sum }}=\sum_{j=1}^{n} t_{\text {pereb }_{j}}, \quad \text { Equation } 17
$$

The subroutine for calculating the cost of an optimised excursion is calculated using the subroutine of Block 2:

1. The cost of an excursionist presence at each point is checked.

2. The cost of staying at all points is attached.

3. The cost of moving between points is added to the total cost of staying at points. If on foot, then 0 , if by transport - the cost of transportation is added.

The introduction of methodological approaches involves the implementation of actions that will ensure the effective use of all work modules.

\section{CONCLUSIONS}

The formation of a holistic tourism system allows to consider the possibility of additional investment in depressed regions and reduce the resulting anthropogenic load. In addition, there is an opportunity to form interstate tourism entities. The authors proposed a model based on international standards and adapted to the current socio-economic situation. The development of the module according to the presented algorithm will allow real-time control in real time, while allowing to develop a received order to create a thematic route for reduced time.

To train employees of a tourism organisation, the following actions are performed: receiving applications for the creation of thematic excursion routes; clarification of a territory of a trip; clarification of a priority valuable object; coordination of a number of objects to visit; coordination of a total travel time; coordination of a type of movement on a route; creating a route thread according to specified parameters of an application. To create faster route thread calculations for employees of tourism enterprises, software was developed that does not require a large investment of time and certain additional skills for its mastering.

\section{REFERENCES}

Akay, B. (2020). Examining the rural tourism experiences of tourists in emerging rural tourism destination: Burdur Province, Turkey. GeoJournal of Tourism and Geosites, 29(2), 534-544. https://doi.org/10.30892/gtg.29212-487 
Backer, E., \& Ritchie, B.W. (2017). VFR travel: A viable market for tourism crisis and disaster recovery? International Journal of Tourism Research, 19(4), 400-411. https://doi.org/10.1002/jtr.2102

Basiurkina, N., Sysoieva, I., Ratushna, J., Kotenko, T., Baistriuchenko, N., \& Sukhanova, A. (2020). Substantiation of the innovation and investment project using the method of real options. International Journal of Management, 11(5), 497-510.

Błażejowski, M., Kwiatkowski, J., \& Gazda, J. (2019). Sources of economic growth: A global perspective. Sustainability, 11(1), 275-281. https://doi.org/10.3390/su11010275

Carmignani, F., \& Moyle, C.L. (2019). Tourism and the output gap. Journal of Travel Research, 58(4), 608-621. https://doi.org/10.1177/0047287518769760

Coca-Stefaniak, J.A. (2019). Marketing smart tourism cities - a strategic dilemma. International Journal of Tourism Cities, 5(4), 513-518. https://doi.org/10.1108/IJTC-12-2019-163

Damian, I.E., \& Suárez-Barraza, M.F. (2015). Process innovation in tourism management. Intangible Capital, 11(2), 147-165. http://dx.doi.org/10.3926/ic.530

Denissova, O., Kozlova, M., Rakhimberdinova, M., Varavin, Y., \& Ordabayeva, M. (2018). International experience in the development of green economy. Journal of Environmental Management and Tourism, 9(3), 564-575.

Diekmann, A., \& McCabe, S. (2016). Social tourism and health. The Routledge Handbook of Health Tourism, 3, 103-112. https://doi.org/10.1080/19407963.2018.1490859

Fedotov, A.M., Murzakhmetov, A.N., \& Dyusembaev, A.E. (2018). Expansion of ideas and processes in social and biological communities. Eurasian Journal of Mathematical and Computer Applications, 6(4), 17-28.

Hair, J.F., Risher, J.J., Sarstedt, M., \& Ringle, C.M. (2019). When to use and how to report the results of PLS-SEM. European Business Review, 31(1), 2-24. https://doi.org/10.1108/EBR-11-2018-0203

Kavun, S., Daradkeh, Y., \& Dhaifullah, M. (2015). Method of the integer linear programming. Mitteilungen Klosterneuburg, 64, 1-13.

Khytrova, O.A., Sysoieva, I.M., Dolha, H.V., Peniuk, V.O., \& Motuzenko, O.V. (2020). Ensuring the growth of enterprises and organizations through the motivation of managerial staff. International Journal of Economics and Business Administration, 2, 219-228.

Kifyak, O. (2019). Resource potential of tourist destinations development. Foreign Trade: Economics, Finance, Law, 4, 60-70.

Li, W. (2017). Design and application of tourism management information system. Agro Food Industry Hi-Tech, 28(3), 2669-2672.

Lin, H. (2018). The practice management of tourism management major graduates in colleges and universities in travel agency. Journal of Advanced Oxidation Technologies, 21(2). https://doi.org/10.26802/jaots.2018.09875

Liying, D. (2018). Information visualization analysis of tourism management research based on web of science. Journal of Advanced Oxidation Technologies, 21(2). https://doi.org/10.26802/jaots.2018.02605

Mazur, V.S. (2019). The modern aspects of tourism business development in Ukraine. Business Inform, 2, 224-230. https://doi.org/10.32983/2222-4459-2019-2-224-230

Prabpriree, M., Maneenetr, T., Siriwong, P., \& Yaipool, K. (2016). Implementing sustainable beach tourism management framework for the royal coast cluster, Thailand. Asian Social Science, 12(8), 146-153. https://doi.org/10.5539/ass.v12n8p146

Qian, J., Law, R., Wei, J., \& Wu, Y. (2019). Trends in global tourism studies: A content analysis of the publications in tourism management. Journal of Quality Assurance in Hospitality and Tourism, 20(6), 753-768. https://doi.org/10.1080/1528008X.2019.1658149

Raj Sharma, V., \& Bisht, K. (2018). Carrying capacity assessment and sustainable tourism management in Agra city, Uttar Pradesh (India). Geojournal of Tourism and Geosites, 25(2), 399-407. https://doi.org/10.30892/gtg.25211-369

Rogerson, C.M., \& Rogerson, J.M. (2019). Tourism, local economic development and inclusion: evidence from Overstrand Local Municipality, South Africa. GeoJournal of Tourism and Geosites, 25(2), 293-308. https://doi.org/10.30892/gtg.25202-360

Rudenko, M.N. (2018). Mechanisms for development and realization of economic capacity of the regional population from the perspective of sociocultural approach. Journal of Advanced Research in Law and Economics, 9(2), 645-663.

Rudenko, M.N., Goloshchapova, L.V., Savvina, O.V., Zamkovoy, A.A., Chernikova, N.V., \& Andryushchenko, O.G. (2016). Innovative activity of financial and industrial groups. International Journal of Economics and Financial Issues, 6(S8), 108-114.

Rudenko, V., Vatseba, V., \& Pidgirna, V. (2019). Management of the tourism industry, Yuriy Fedkovich National University, Chernivtsi.

Sakulyeva, T. (2020). Towards the development of innovative technologies for the "mobility as a Service" system. Journal of Physics: Conference Series, $1515(3), 032003$.

Sayabaev, K., Nurgaliyeva, Z., Temirova, A., Kasenova, A., Dzhamburbaeva, M., Zhangirova, R., Sadvokasova, K., Kemel, M., Kodasheva, G., Shamuratova, N., \& Zhansagimova, A. (2016). Finance, franchise and their impact on tourism. Journal of Internet Banking and Commerce, 21 (3), 229.

Sharifzadeh, A.E., Khakpoor, B.A., \& Revashty, A.M. (2020). Tourism in border cities. Geojournal of Tourism and Geosites, 28(1), 52-66. https://doi.org/10.30892/gtg.28104-451

Sherali, H.D., \& Driscoll, P.J. (2019). Evolution and state-of-the-art in integer programming. Journal of Computational and Applied Mathematics, 124(1/2), 319-340.

Shtal, T.V., Lytovchenko, I., \& Poliakova, H.A. (2019). Development of professional competency of managerial staff on the basis of acmeological approach. Journal of Advanced Research in Law and Economics, 9(4), 1481-1488.

Shtal, T.V., Uvarova, A., \& Ostapenko, I.I. (2018). Evaluation of the influence of external environmental factors on logistics activities: Case study of Ukrainian retail trade enterprises. Journal of Environmental Management and Tourism, 9(7), 1593-1605.

Smoliy, V.A., Fedorchenko, V.K., \& Tsybukh, V.I. (2006). Encyclopedic dictionary-reference book on tourism, Slovo, Kyiv.

Song, H. (2016). Evaluating the practice teaching of tourism management based on AHP method. RISTI-Revista Iberica de Sistemas e Tecnologias de Informacao, 14, 30-36.

Song, H. (2017). An empirical analysis of comprehensive evaluation index system for tourism management professional practice teaching. Boletin Tecnico/Technical Bulletin, 55(6), 657-661.

Todd, L., Leask, A., \& Ensor, J. (2017). Understanding primary stakeholders' multiple roles in hallmark event tourism management. Tourism Management, 59, 494-509. https://doi.org/10.1016/j.tourman.2016.09.010

Towner, N. (2016). How to manage the perfect wave: Surfing tourism management in the Mentawai Islands, Indonesia. Ocean and Coastal Management, 119, 217-226. https://doi.org/10.1016/j.ocecoaman.2015.10.016

Wondirad, A., Tolkach, D., \& King, B. (2020). Stakeholder collaboration as a major factor for sustainable ecotourism development in developing countries. Tourism Management, 78, Article number 104024. https://doi.org/10.1016/j.tourman.2019.104024

Yuexi, W., \& Feng, X. (2018). Feasibility analysis of tourism management teaching based on internet e-commerce mode. Journal of Advanced Oxidation Technologies, 21(2). https://doi.org/10.26802/jaots.2018.06172 